\section{Acid-labile Ribose as an Indicator of Ribonucleic Acid Base Composition}

THE lability to acid of purine ribomononucleotide $\mathrm{N}^{9}$. glycosidic linkages, as opposed to the stability of pyrimidjne ribomononucleotide $\mathrm{N}^{3}$-glycosidic linkages, is well documented (for example, ref. 1). It has, however, been noted that the latter linkage is not completely resistant, in the cases of cytidylic and uridylic acids, under the conditions of the Bial reaction of their pentose moieties with orcinol ${ }^{2}$.

The acid lability of purine mononucleotides has been used to estimate the purine/pyrimidine ratios of yeast whole-cell ribonucleic acid ${ }^{3}$ by recalculation from the molar ratios of acid-labile ribose/nucleotide phosphorus. The validity of this method depends on the freedom of the examined RNA from extraneous, non-nucleic acid phosphorus and the hydrolytic release only of purine ribose and its reaction with orcinol. The first condition was satisfactorily achieved; an examination of the second is reported here.

Approximately $1 \mathrm{mM}$ aqueous solutions of mixed $2^{\prime}$ and $3^{\prime}$ isomers of GMP, AMP, CMP and UMP (Sigma) were prepared. Quadruplicate aliquots of $1 \mathrm{ml}$. were used in estimating acid-labile ribose by a modification ${ }^{3}$ of the method of Ceriottit. The results, presented as the molar ratios of acid-labile ribose/orthophosphate (estimated by the method of Boltz and Mellon ${ }^{5}$ ), are shown in Table 1.

Table 1. Molar Ratios of AcID-Labile Ribose to OrThophosphate

$\begin{array}{ccc} & \text { IN RNA Mononucleotides } \\ \text { Nucleotide } & \text { Expected } & \text { Molar ratio } \\ \text { GMP } & 1.0 & 0.985 \pm 0.011 \\ \text { AMP } & 1.0 & 1 \cdot 000 \pm \pm 0.020 \\ \text { CMP } & 0 & 0.0097 \pm 0.003 \\ \text { UMP } & 0 & 0.062 \pm 0.003\end{array}$

Under the conditions of ribose estimation (final concentration of hydrochloric acid, $5 \mathrm{~N}$ ) hydrolysis of GMP and AMP is virtually complete. Only UMP of the pyrimidine nucleotides contributed significant colour.

Acid-labile ribose was similarly estimated in artificial mixtures of the four nucleotides. Ribose/phosphate ratios, recalculated to purine/pyrimidine ratios, are shown in Table 2. 'Expected' ratios were based directly on molar proportions of nucleotides, given 100 per cent purine mononucleotide hydrolysis and no pyrimidine mononucleotide hydrolysis, while 'corrected' ratios included allowances for $98 \cdot 5,100,1$ and 6 per cent hydrolysis, respectively, for GMP, AMP, CMP and UMP.

Table 2. Purine/Pyrimidine Ratios of Artificial Mixtures of RNA MONONUCLEOTIDES

\begin{tabular}{rrrrrrr} 
& \multicolumn{3}{c}{ Molar proportions } & \multicolumn{3}{c}{$\begin{array}{c}\text { Purine/pyrimidine ratio } \\
\text { Expec- }\end{array}$ Correc- } \\
GMP & AMP & CMP & UMP & ted & ted & Found \\
$\mathbf{2 4 . 7}$ & 26.0 & $\mathbf{2 6 . 8}$ & 22.5 & 1.03 & 1.08 & 1.08 \\
29.6 & 29.2 & 20.4 & 20.7 & 1.43 & 1.49 & 1.49 \\
24.0 & 21.0 & $\mathbf{2 5 . 0}$ & $\mathbf{3 0 . 0}$ & 0.82 & 0.88 & 0.88
\end{tabular}

Agreement between corrected and experimental values of 'purine/pyrimidine' ratios was good. Consistent overestimate of the true value, of the order of $0.05-0.06$ unit, is apparent, so that precise estimates of purine/pyrimidine ratios must still depend on separation of the four nucleotides in hydrolysates of RNA. However, the method provides a useful guide before the more time-consuming separations are undertaken.

M.B.T. Research Laboratory Pty., Ltd.,*

D. I. EDDY

Darlinghurst,

New South Wales.

* A subsidiary of Mauri Brothers and Thomson, Ltd.

${ }^{1}$ Baddiley, J., The Nucleic Acids, 1, 137 (Academic Press, New York, 1955).

${ }^{2}$ Hutchison, W. C., and Munro, H. N., Analyst, 86, 768 (1961).

${ }^{3}$ Eddy, D. I., Biochim. Biophys. Acta, 80, 373 (1964).

4 Ceriotti, G., J. Biol. Chem., 214, 59 (1955).

${ }^{5}$ Boltz, D. F., and Mellon, M, G., Anal. Chem., 19, 873 (1947).

\section{Oxidation of $\beta$-Carotene by Hydroperoxides}

IT is generally believed that bleaching of $\beta$-carotene concurrent with lipoxidase catalysed oxidations of fixed oils occurs by reaction with intermediates of the autoxidation process. This view, which appears to be based originally on the observation that loss of colour proceeds only very slowly in the presence of previously peroxidized fat ${ }^{i}$, has led to a general conclusion that hydroperoxides do not oxidize carotenoids readily ${ }^{2}$. Recent investigations of the action of tetralin hydroperoxide, concerned with product analysis, have again emphasized that the reaction proceeds only very slowly ${ }^{3}$.

We have now been concerned with rates of oxidation of $\beta$-carotene by tert-butyl hydroperoxide over a series of concentrations--using hydroperoxide/pigment molar ratios of 5-200/1. - and find that loss of $\beta$-carotene occurs in a regular manner for each amount of hydroperoxide used.

To 0.1 per cent $(0.0186$ mole per cent) solution of $\beta$-carotene in chloroform $(2 \mathrm{ml}$.) was added the required amount of pure tert-butyl hydroperoxide and the mixture, diluted to constant volume $(2.5 \mathrm{ml}$.) with more chloroform, kept at $25^{\circ}$ in the dark. The small flasks were flushed with nitrogen and access of oxygen prevented so far as possible during handling. Residual $\beta$-carotene was separated from oxidation products by chromatography on alumina using light petroleum (b.p. $60^{\circ}-80^{\circ}$ ) for development, and estimated spectrophotometrically. Results are illustrated in Fig. 1.

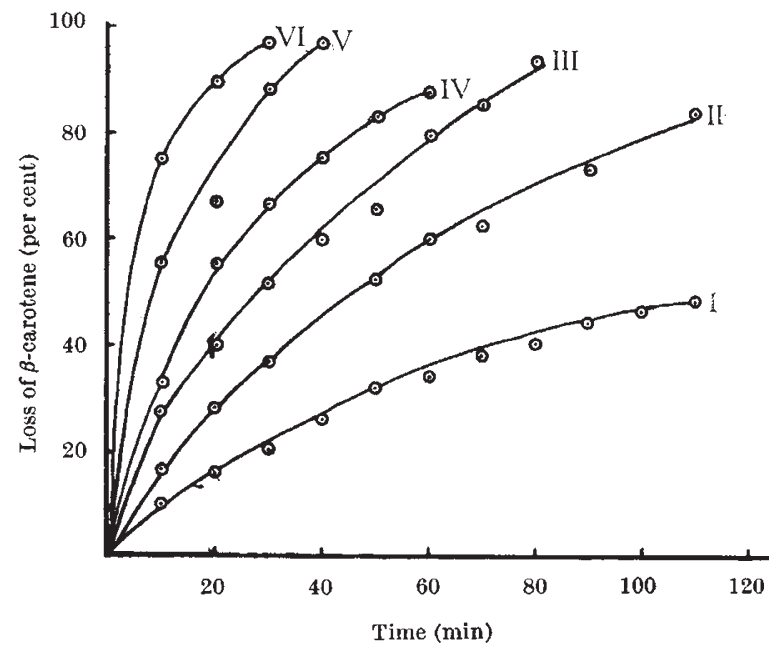

Fig. 1. Oxidation of 6 -carotene by tert-butyl hydroperoxide in chloroform at $25^{\circ}$. Moles hydroperoxide per mole of pigment: I, $5 ;$ II, 10 ;
III, $20 ;$ IV, $50 ; \mathrm{V}, 100 ;$ VI, 200

It will be observed that even with the lowest concentration of hydroperoxide used ( 5 molar ratio), loss of $\beta$-carotene is recognizable after $10 \mathrm{~min}$. Indications are that the initial reaction is first order with respect to the $\beta$-carotene but stepwise increase in the concentration of hydroperoxide used does not lead to a proportional increase in the rate of loss of pigment. Although all solutions ultimately are completely bleached, due to the continued action of hydroperoxide on the initial products, nevertheless the early losses of $\beta$-carotene are masked by a darkening and change in shade of colour of the solution. This is easily visible to the eye, but the trends of change are better revealed by the Lovibond readings of Table 1 .

While the intensity of colour precludes use of the readings other than as indicating the general trend of change, nevertheless they provide a more adequate representation of the process than vaguer descriptions of appearance visually. In particular the introduction, rise and gradual subsequent fall in blue components should be noted. 